\title{
Non-invasive oxygenation support in acutely hypoxemic COVID-19 patients admitted to the ICU: a multicenter observational retrospective study
}

Pedro David Wendel-Garcia ${ }^{1 \dagger}$, Arantxa Mas ${ }^{2}$, Cristina González-Isern³ ${ }^{3}$, Ricard Ferrer ${ }^{4}$, Rafael Máñez ${ }^{5}$, Joan-Ramon Masclans ${ }^{6}$, Elena Sandoval ${ }^{7}$, Paula Vera $^{8}$, Josep Trenado $^{9}$, Rafael Fernández ${ }^{10}$, Josep-Maria Sirvent ${ }^{11}$, Melcior Martínez ${ }^{12}$, Mercedes Ibarz ${ }^{13}$, Pau Garro ${ }^{14}$, José Luis Lopera ${ }^{15}$, María Bodí ${ }^{16}$, Joan Carles Yébenes-Reyes ${ }^{17}$, Carles Triginer ${ }^{18}$, Imma Vallverdú ${ }^{19}$, Anna Baró ${ }^{20}$, Fernanda Bodí ${ }^{21}$, Paula Saludes ${ }^{22}$, Mauricio Valencia ${ }^{23}$, Ferran Roche-Campo ${ }^{24}$, Arturo Huerta ${ }^{25}$, Francisco José Cambra ${ }^{26}$, Carme Barberà27 Jorge Echevarria ${ }^{28}$, Óscar Peñuelas ${ }^{29}$, Jordi Mancebo $0^{8,30^{*}+}$ (i) and for the UClsCAT study group

\begin{abstract}
Background: Non-invasive oxygenation strategies have a prominent role in the treatment of acute hypoxemic respiratory failure during the coronavirus disease 2019 (COVID-19). While the efficacy of these therapies has been studied in hospitalized patients with COVID-19, the clinical outcomes associated with oxygen masks, high-flow oxygen therapy by nasal cannula and non-invasive mechanical ventilation in critically ill intensive care unit (ICU) patients remain unclear.

Methods: In this retrospective study, we used the best of nine covariate balancing algorithms on all baseline covariates in critically ill COVID-19 patients supported with $>10 \mathrm{~L}$ of supplemental oxygen at one of the 26 participating ICUs in Catalonia, Spain, between March 14 and April 15, 2020.

Results: Of the 1093 non-invasively oxygenated patients at ICU admission treated with one of the three stand-alone non-invasive oxygenation strategies, 897 (82\%) required endotracheal intubation and 310 (28\%) died during the ICU stay. High-flow oxygen therapy by nasal cannula $(n=439)$ and non-invasive mechanical ventilation $(n=101)$ were associated with a lower rate of endotracheal intubation ( $70 \%$ and $88 \%$, respectively) than oxygen masks ( $n=553$ and $91 \%$ intubated), $p<0.001$. Compared to oxygen masks, high-flow oxygen therapy by nasal cannula was associated with lower ICU mortality (hazard ratio 0.75 [95\% Cl 0.58-0.98), and the hazard ratio for ICU mortality was 1.21 [95\% Cl 0.80-1.83] for non-invasive mechanical ventilation.
\end{abstract}

Conclusion: In critically ill COVID-19 ICU patients and, in the absence of conclusive data, high-flow oxygen therapy by nasal cannula may be the approach of choice as the primary non-invasive oxygenation support strategy.

\footnotetext{
*Correspondence: JMancebo@santpau.cat

†Pedro David Wendel-Garcia and Jordi Mancebo have contributed equally.

${ }^{8}$ Intensive Care Department, Hospital de La Santa Creu I Sant Pau, Barcelona, Spain

Full list of author information is available at the end of the article
} permits use, sharing, adaptation, distribution and reproduction in any medium or format, as long as you give appropriate credit to the original author(s) and the source, provide a link to the Creative Commons licence, and indicate if changes were made. The images or other third party material in this article are included in the article's Creative Commons licence, unless indicated otherwise in a credit line to the material. If material is not included in the article's Creative Commons licence and your intended use is not permitted by statutory regulation or exceeds the permitted use, you will need to obtain permission directly from the copyright holder. To view a copy of this licence, visit http://creativecommons.org/licenses/by/4.0/. The Creative Commons Public Domain Dedication waiver (http://creativeco mmons.org/publicdomain/zero/1.0/) applies to the data made available in this article, unless otherwise stated in a credit line to the data. 
Keywords: COVID-19, Intensive care, Non-invasive oxygenation, Acute hypoxemic respiratory failure

\section{Background}

The coronavirus disease 2019 (COVID-19), caused by the severe acute respiratory syndrome coronavirus 2 (SARS-CoV-2), has generated an unprecedented demand for intensive care resources to deliver supportive care using non-invasive oxygenation support and invasive mechanical ventilation [1]. Large studies have provided data regarding baseline clinical characteristics of patients admitted to intensive care units (ICU), the need for invasive mechanical ventilation, and outcomes of mechanically ventilated patients [2-10].

During the pandemic, patients with acute hypoxemic respiratory failure admitted to the ICU and not in need of emergent intubation of the trachea have mainly been treated with non-invasive oxygenation strategies [1]. These methods include standard non-rebreather oxygen masks (oxygen mask), high-flow oxygen therapy administered through large-bore nasal cannulas (HFT), and noninvasive positive pressure ventilation (NIV) techniques $[1,2,11]$. The choice for using one type of oxygenation support over another has likely been based on local recommendations, personal experience, and availability of devices.

The difference of opinions regarding the optimal technique for non-invasive oxygenation support is ample, but the consequences and relevant clinical outcomes of the various usual care strategies in critically ill COVID19 patients admitted to an ICU remain unclear [12-15]. Thus, our main objective was to evaluate the impact of three stand-alone non-invasive oxygenation strategies on intubation rates and ICU mortality at 90 days after admission of critically ill patients with COVID-19-associated acute hypoxemic respiratory failure. We hypothesized that the various non-invasive oxygenation support strategies had no impact on intubation and ICU mortality rates.

\section{Methods}

We retrospectively analysed a cohort of patients admitted to ICUs in the Spanish autonomous community of Catalonia between March 14 and April 15, 2020. The official census population of Catalonia at the time was $7,780,479$ inhabitants. At the start of the pandemic, the Catalonian public health system had approximately 500 adult ICU beds in its 26 hospitals, and 13 private hospitals had an additional 100-120 ICUs beds for adults. An invitation to participate in the study was sent to the head of department at all the intensive care medicine departments in Catalonia at the end of April 2020. In view of the nature of the study, the ethics committee at the coordinating centre (Hospital Universitari de la Santa Creu i Sant Pau, Barcelona) approved the study protocol (UCIS-CAT 20/151 OBS) and waived the need for informed consent. Participating centres complied with all local requirements.

\section{Inclusion and exclusion criteria}

The inclusion criteria were age 18 years or older, patient admitted to an ICU, clinical signs and symptoms compatible with COVID-19 pneumonia, a positive realtime reverse-transcriptase polymerase chain reaction test for SARS-CoV-2 obtained from a nasopharyngeal swab, bilateral infiltrates in the chest X-ray, need for supplemental oxygen to keep arterial oxygen saturation measured with a pulse oximeter $\left(\mathrm{SpO}_{2}\right)$ above $90 \%$, and admission at one of the participating centres' ICU between March 14 and April 15, 2020. All patients were candidates for intubation and mechanical ventilation at the time of ICU admission. Decisions regarding intubation of the trachea were based on clinical grounds and judgment of the intensivist in charge.

Only patients who had been treated exclusively with a single non-invasive oxygenation technique during their ICU stay were included in this analysis: oxygen mask at a rate of more than $10 \mathrm{~L}$ oxygen/minute, HFT administered through a heated humidifier at a gas flow rate above $30 \mathrm{~L} /$ minute and a fraction of inspired oxygen $\left(\mathrm{FiO}_{2}\right)$ of at least 0.5 , or NIV with a $\mathrm{FiO}_{2}$ of at least 0.5 (irrespective of interface, mode and ventilator type used). The choice of non-invasive oxygenation technique was at the discretion of each participating ICU and was based on local recommendations and availability of devices. The day of ICU admission was defined as day 0 . Patients were excluded from our analysis in three situations: first, they were intubated and mechanically ventilated before ICU admission because the context and conditions of intubation were unknown; second, they were intubated immediately after ICU admission (within $3 \mathrm{~h}$ ) because the attempt at noninvasive oxygenation support was considered clinically unsuccessful; and third, they received oxygen supplementation either by nasal prongs or by any combination of oxygen mask, HFT and NIV (Fig. 1). Patients receiving a combination of multiple non-invasive oxygenation support techniques were not analysed as the order of administration and the reasons for change could not be precisely elucidated, thus introducing an unquantifiable allocation bias into the analysis. 


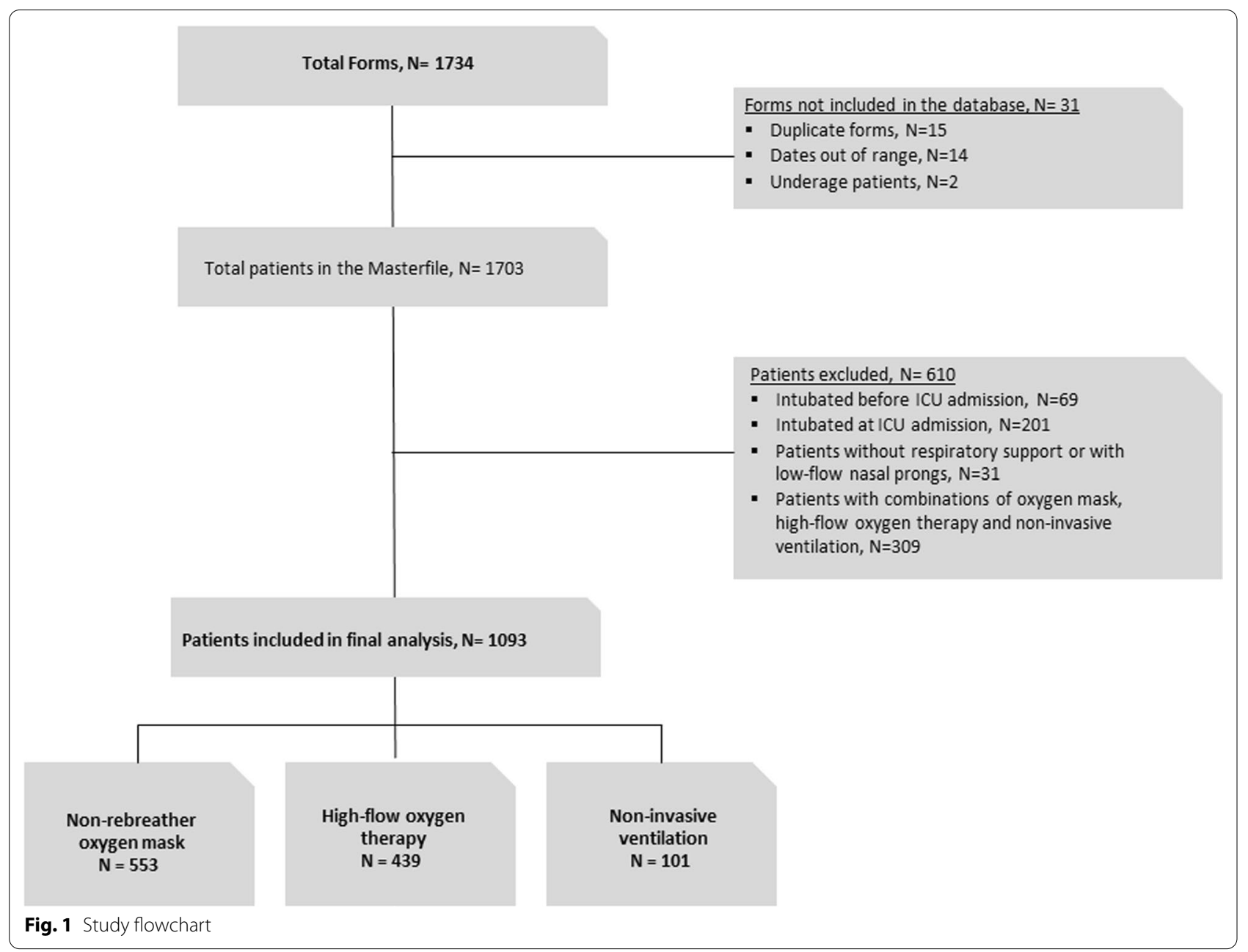

\section{Data collection}

The principal investigator at each centre filled in a standardized case report form for each patient included in the study. Data regarding demographic variables, laboratory data at admission, type of non-invasive and invasive oxygenation support, variables related to gas exchange and respiratory system mechanics obtained shortly after endotracheal intubation, and ICU outcome status at 90 days from ICU admission were processed from the independent case report forms and stored in a single master file. Patients were followed in the ICU until day 90 post-admission or until ICU discharge, whichever occurred first. This file was reviewed independently by three investigators (PDWG, CGI and JM). The principal investigators at each centre were contacted to solve any errors or missing data. Following this process, the master file was closed.

Once intubated, patients who met acute respiratory distress syndrome (ARDS) criteria were classified in mild, moderate and severe oxygenation phenotypes, as described [16]. Driving airway pressure was calculated as the difference between plateau airway pressure and set positive end-expiratory pressure (PEEP). Compliance of the respiratory system was calculated as tidal volume divided by driving airway pressure. The ventilatory ratio and estimated physiological deadspace fraction were calculated as previously described by Sinha et al. [17] and Morales-Quinteros et al. [18], respectively.

\section{Missing data}

To account for missing data (Additional file 1: Table s1), we performed multiple imputations by fully conditional specification with predictive mean matching under the missing at random assumption [19]. Further details regarding the imputation method used are presented in Additional file 1: Appendix 1, Additional file 1: Fig. s1, Additional file 1: Fig. S2 and Additional file 1: Table s2. 


\section{Statistical analysis}

To enable causal inference of the average treatment effect associated with each oxygenation support strategy, we evaluated the baseline covariate balance at ICU admission. Covariate balancing refers to a group of statistical methods used to enable exchangeability of exposed and unexposed subjects to one or multiple treatments in order to minimize confounding. Applying a weight on each individual subject generates a standardized pseudo-population, in which causal treatment effect inference is possible. Nine covariate balancing methods considering all baseline covariates at ICU admission were tested against each other (see Additional file 1: Appendix 2). The best covariate balancing method (standardized mean deviation $<0.1$ and variance ratio $<2$ ) was used for all subsequent analyses [20]. A detailed description on the covariate balancing method selection is also shown in Additional file 1: Appendix 2 and Additional file 1: Figs. s3 and s4.

Univariable and multivariable Cox proportional hazard models coupled to the Kaplan-Meier estimator, with and without random frailty terms for betweencentre variability effect, were used to analyse the effects of the different oxygenation support strategies on the incidence of intubation and ICU mortality. The effects are represented by hazard ratios and their $95 \%$ confidence interval (CI). A time-varying Cox proportional hazards model was used to investigate the effect of time between ICU admission and intubation on 90-day ICU mortality. Patients discharged alive from the ICU were considered to be alive at day 90. Survival distributions among the various oxygenation support strategies were compared using the log-rank test. Proportional hazard assumptions were assessed by inspection of Schoenfeld residuals.

Ventilator-free survival days were defined as the cumulative time in the first 30 days of ICU admission without the need for invasive mechanical ventilation. Patients who died within the first 30 days were assigned 0 ventilator-free days. Population characteristics were compared using analysis of variance or the Kruskal-Wallis test, as appropriate, and the chi-squared test for categorical variables. Statistical analysis was performed through a fully scripted data management pathway using the $\mathrm{R}$ environment for statistical computing version 4.1.0. No power calculations were performed due to the observational nature of this cohort study. A two-sided $p<0.05$ was considered statistically significant. Values are given as medians and [interquartile ranges] or counts and percentages as appropriate.

\section{Results}

Twenty-six centres participated in the study, 20 of the 26 public health system hospitals in Catalonia and 6 of 13 private care centres. The study thus reflects the care provided to patients in 438 of the 620 adult ICU beds available in Catalonia at the beginning of the pandemic, 370 pertaining to the public system and 68 to the private health system (see Additional file 1: Appendix 3).

A total of 1703 critically ill COVID-19 patients were admitted to the participating ICUs between March 14 and April 15, 2020. Figure 1 shows the study flowchart and Additional file 1: Table s3 shows the main characteristics and outcomes for the overall unbalanced population. Three-hundred and nine patients were treated with combinations of non-invasive respiratory support techniques and were excluded from the analysis to allow a clear differentiation between individual therapies. Overall, these patients had a $72 \%$ intubation rate $(222 / 309)$ and the ICU mortality rate up to day 90 post-admission was $27.5 \%(85 / 309)$.

\section{Population analysed and matching analysis}

The final analysis included 1093 patients treated with a non-invasive oxygenation support strategy during their ICU stay: 553 (51\%) with oxygen mask, 439 (40\%) with HFT, and 101 (9\%) with NIV. Their main characteristics and outcomes are shown in Additional file 1: Table s4.

Among the various balancing algorithms tested, we employed the targeted stable balancing weights using the optimization algorithm. This algorithm minimized standard mean deviation $(<0.0001)$ and variance ratios $(\leq 1.7)$ between oxygenation support strategies for all variables and presented consistent and moderate weights $(1 \pm 0.35)$ for all patients (Additional file 1: Fig. s5, Additional file 1: Fig. s6, Additional file 1: Fig. s7).

\section{Characteristics of the analysed population}

Baseline characteristics across oxygenation support strategies were identical after covariate balancing (Table 1). Patients were mainly male $(68 \%)$ with a median age of 63 [54-70] years. The median time between hospital and ICU admission was 1 day [0-3 days]. The overall intubation rate was $82 \%(897 / 1093)$. A total of 501 out of 553 (91\%) patients treated with oxygen mask were eventually intubated and mechanically ventilated as opposed to 307 out of $439(70 \%)$ of those treated with HFT and 89 out of $101(88 \%)$ of those treated with NIV $(p<0.001)$. The number of ventilator-free days was higher in the HFT group than in the oxygen mask and NIV groups $(p<0.001)$.

Table 2 shows the characteristics of patients who eventually required intubation and mechanical ventilation, after covariate balancing. The median time from ICU 
Table 1 Demographics, baseline characteristics at intensive care unit admission and overall outcome obtained after covariate balancing*

\begin{tabular}{|c|c|c|c|c|c|c|c|}
\hline & Overall & Oxygen mask & High-flow oxygen therapy & $\begin{array}{l}\text { Non-invasive } \\
\text { ventilation }\end{array}$ & $p$ & SMD & VR \\
\hline & $n=1093$ & $n=553$ & $n=439$ & $n=1011$ & & & \\
\hline Age (years) & $63[54-70]$ & $64[54-70]$ & $62[54-70]$ & $63[53-69]$ & 0.904 & $<0.001$ & 1.11 \\
\hline Sex (female) & $354(32)$ & $179(32)$ & $142(32)$ & $33(32)$ & 1 & $<0.001$ & - \\
\hline Body mass index $\left(\mathrm{kg} \cdot \mathrm{m}^{-2}\right)$ & $28[26-31]$ & $28[25.31]$ & $28[26-31]$ & $28[26-31]$ & 0.914 & $<0.001$ & 1.23 \\
\hline $\begin{array}{l}\text { Time from hospital admission } \\
\text { to ICU admission [days] }\end{array}$ & $1[0-3]$ & $1[0-3]$ & 1 [0-3] & $2[1-3]$ & 0.553 & $<0.001$ & 1.22 \\
\hline Comorbidities, n (\%) & & & & & & & \\
\hline Cardiovascular & $520(48)$ & $263(48)$ & $209(48)$ & $48(48)$ & 1 & $<0.001$ & - \\
\hline Diabetes & $226(21)$ & $114(21)$ & $91(21)$ & $21(21)$ & & & \\
\hline Cancer & $80(7)$ & $41(7)$ & $32(7)$ & $7(7)$ & & & \\
\hline COPD & $79(7)$ & $40(7)$ & $32(7)$ & $7(7)$ & & & \\
\hline Immunosupression & $63(6)$ & $32(6)$ & $25(6)$ & $6(6)$ & & & \\
\hline Leucocytes (G/l) & $9[6-12]$ & $9[6-12]$ & 9 [6-12] & $9[7-12]$ & 0.782 & $<0.001$ & 1.25 \\
\hline Lymphocytes (G/l) & $0.7[0.5-1.0]$ & $0.7[0.5-1.0]$ & $0.8[0.5-1.0]$ & $0.7[0.5-1.0]$ & 0.551 & $<0.001$ & 1.28 \\
\hline Neutrophil/ lymphocyte ratio & $10[7-17]$ & $11[6-18]$ & $10[7-17]$ & $10[7-18]$ & 0.688 & $<0.001$ & 1.46 \\
\hline Procalcitonin ( $\mu \mathrm{g} / \mathrm{l})$ & $0.3[0.1-0.6]$ & $0.3[0.1-0.6]$ & $0.3[0.1-0.6]$ & $0.2[0.1-0.5]$ & 0.254 & $<0.001$ & 1.7 \\
\hline C-reactive protein (mg/l) & $113[23-222]$ & $118[30-217]$ & $104[17-227]$ & $114[30-227]$ & 0.296 & $<0.001$ & 1.42 \\
\hline Lactate $(\mathrm{mmol} / \mathrm{l})$ & $1.4[1.1-1.9]$ & $1.3[1.0-1.9]$ & $1.4[1.1-1.9]$ & $1.4[1.2-1.8]$ & 0.052 & $<0.001$ & 1.47 \\
\hline Interleukin-6 (ng/l) & $129[50-329]$ & $132[50-304]$ & $118[60-332]$ & $130[43-354]$ & 0.855 & $<0.001$ & 1.34 \\
\hline D-dimers $(\mu \mathrm{g} / \mathrm{l})$ & 1145 [560-2965] & $1262[611-3058]$ & $1040[494-2760]$ & $1190[558-3793]$ & 0.07 & $<0.001$ & 1.57 \\
\hline Ferritin $(\mu \mathrm{g} / \mathrm{l})$ & 1387 [760-2259] & 1325 [779-2254] & $1465[742-2215]$ & $1382[722-2356]$ & 0.91 & $<0.001$ & 1.58 \\
\hline Intubation, n (\%) & $897(82)$ & $501(91)$ & $307(70)$ & $89(88)$ & $<0.001$ & & \\
\hline Length of ICU stay (days) & $14[7-26]$ & $14[7-26]$ & $13[7-26]$ & $13[8-24]$ & 0.958 & & \\
\hline Ventilator-free survival ${ }^{\dagger}$ (days) & $12[0-24]$ & $8[0-23]$ & $15[0-30]$ & $11[0-24]$ & $<0.001$ & & \\
\hline ICU mortality, n (\%) & $310(28)$ & $167(30)$ & $106(24)$ & $37(36)$ & 0.041 & & \\
\hline
\end{tabular}

Quantitative data are expressed as median [interquartile range]. $p$ values are given for the difference between respiratory strategies. Standardized mean differences $(S M D)$ reflect the maximal mean difference between groups. Variance ratios (VR) reflect the maximal higher-order moments and interactions between groups. COPD—chronic obstructive pulmonary disease; CRP—C-reactive protein; ICU—intensive care unit; PCT—Procalcitonin. $†$ Calculated at 30 days post-intensive care unit admission; patients deceased were assigned 0 ventilator free days

*By applying a weight on each individual subject, a standardized pseudo-population is generated, which slightly differs from the original population (e-Table 4). Causal treatment effect inference is possible in this pseudo-population

**Includes any of the following: arterial hypertension, ischemic heart disease, acute cerebrovascular events

admission to endotracheal intubation was 0 [0-0] days in the oxygen mask group, 0 [0-1] days in the HFT group, and $0[0-1]$ days in the NIV group $(p<0.001)$. Among the 897 intubated patients, 824 (92\%) had an ARDS and this was moderate-to-severe in 571 (69\%).

Figure 2 shows the cumulative proportion of intubation over time according to the various non-invasive oxygenation support techniques. As compared to oxygen mask, the hazard ratio for intubation in HFT treated patients was 0.45 (95\% CI 0.39-0.53) and 0.67 (95\% CI 0.53-0.85) for NIV treated patients.

\section{Mortality}

The cumulative proportion of ICU survival, evaluated up to 90 days of ICU admission, differed significantly according to the initially chosen non-invasive oxygenation strategy $(p=0.02)$ (Fig. 3a). As compared to patients treated with an oxygen mask, the hazard ratio for ICU mortality was 0.75 [95\% CI 0.58-0.98] for HFT ventilated patients, and 1.21 [95\% CI 0.8-1.83] for NIV treated patients.

In intubated and mechanically ventilated patients, the 90-day ICU mortality did not differ $(\mathrm{p}=0.2)$ between groups (Fig. 3b).

\section{Secondary analyses}

The time from ICU admission to intubation showed no influence on static respiratory system compliance, driving airway pressure, or $\mathrm{PaO}_{2} / \mathrm{FiO}_{2}$ ratio as measured shortly after intubation (Additional file 1: Fig. s8, 
Table 2 Ventilator settings and gas-exchange parameters shortly after intubation and outcome in intubated patients

\begin{tabular}{|c|c|c|c|c|c|}
\hline & Overall $n=897$ & Oxygen mask $n=501$ & $\begin{array}{l}\text { High-flow oxygen } \\
\text { therapy } n=307\end{array}$ & $\begin{array}{l}\text { Non-invasive } \\
\text { ventilation } \\
n=89\end{array}$ & $p$ \\
\hline Time from ICU admission to intubation [days] & $0[0-1]$ & $0[0-0]$ & $0[0-1]$ & $0[0-1]$ & $<0.001$ \\
\hline \multicolumn{6}{|l|}{ ARDS classification ${ }^{\dagger}, \mathrm{n}(\%)$} \\
\hline No ARDS & $73(8)$ & $48(9)$ & $18(6)$ & $7(8)$ & 0.264 \\
\hline Mild & $253(28)$ & $151(30)$ & $84(27)$ & $18(20)$ & \\
\hline Moderate & $451(50)$ & $238(48)$ & $159(52)$ & $54(61)$ & \\
\hline Severe & $120(14)$ & $64(13)$ & $46(15)$ & $10(11)$ & \\
\hline $\mathrm{FiO}_{2}(\%)$ & $60[50-80]$ & $60[50-80]$ & $60[50-70]$ & $60[45-80]$ & 0.444 \\
\hline $\mathrm{PaO}_{2}(\mathrm{mmHg})$ & $97[79-126]$ & $98[80-131]$ & $98[78-122]$ & $91[78-113]$ & 0.19 \\
\hline $\mathrm{PaO}_{2} / \mathrm{FiO}_{2}(\mathrm{mmHg})$ & $171[126-229]$ & 173 [124-238] & $174[127-228]$ & $157[124-205]$ & 0.487 \\
\hline $\mathrm{PaCO}_{2}(\mathrm{mmHg})$ & $46[40-54]$ & $46[40-54]$ & $47[40-54]$ & $46[38-57]$ & 0.993 \\
\hline $\mathrm{pH}$ & $7.35[7.29-7.4]$ & $7.35[7.28-7.4]$ & $7.35[7.29-7.41]$ & $7.35[7.28-7.4]$ & 0.57 \\
\hline Respiratory rate (1/min) & $22[20-25]$ & $22[20-25]$ & $22[20-25]$ & $22[20-26]$ & 0.555 \\
\hline Tidal volume/ideal body weight [ml/kg] & $6.7[6.0-7.5]$ & $6.7[6.0-7.5]$ & $6.7[6.1-7.6]$ & $6.7[5.7-7.3]$ & 0.27 \\
\hline $\operatorname{PEEP}\left(\mathrm{cmH}_{2} \mathrm{O}\right)$ & $12[10-14]$ & $12[10-14]$ & $12[10-14]$ & $14[12-15]$ & $<0.001$ \\
\hline Plateau airway pressure $\left(\mathrm{cmH}_{2} \mathrm{O}\right)$ & 25 [23-28] & $25[22-28]$ & $25[23-28]$ & $26[24-28]$ & 0.13 \\
\hline Driving airway pressure $\left(\mathrm{cmH}_{2} \mathrm{O}\right)$ & $12[10-15]$ & $12[10-15]$ & $12[10-15]$ & $12[10-15]$ & 0.745 \\
\hline Compliance rs $\left(\mathrm{ml} / \mathrm{cmH}_{2} \mathrm{O}\right)$ & $35[28-44]$ & $34[28-42]$ & 35 [27-45] & 33 [27-43] & 0.591 \\
\hline Ventilatory ratio * & $1.9[1.5-2.3]$ & $1.9[1.5-2.3]$ & $1.8[1.5-2.3]$ & $1.8[1.4-2.3]$ & 0.837 \\
\hline Estimated physiological dead-space fraction (\%) ** & $54[42-64]$ & $54[43-63]$ & 55 [39-64] & $51[43-63]$ & 0.823 \\
\hline Length of mechanical ventilation (days) & $14[7-25]$ & $14[7-24]$ & $16[9-26]$ & $12[7-22]$ & 0.031 \\
\hline Length of ICU stay (days) & $17[10-28]$ & $16[9-27]$ & $19[12-31]$ & $15[9-26]$ & 0.004 \\
\hline ICU mortality, n (\%) & $297(33)$ & $164(33)$ & $96(31)$ & $37(41)$ & 0.275 \\
\hline
\end{tabular}

Quantitative data are expressed as median [interquartile range]. $P$ values are given for the difference between respiratory strategies. ARDS—acute respiratory distress syndrome; ICU —intensive care unit; $\mathrm{PaO}_{2}$ - partial pressure of arterial oxygen; $\mathrm{FiO}_{2}$ - fraction of inspired oxygen; $\mathrm{PaCO}_{2}$ - partial pressure of arterial carbon dioxide; PEEP-positive end-expiratory pressure; Compliance rs-compliance of the respiratory system

${ }^{\dagger}$ Mild: $200 \mathrm{mHg}<\mathrm{PaO}_{2} / \mathrm{FiO}_{2} \leq 300 \mathrm{mmHg}$; Moderate: $100 \mathrm{mHg}<\mathrm{PaO}_{2} / \mathrm{FiO}_{2} \leq 200$ mmHg; Severe: $\mathrm{PaO}_{2} / \mathrm{FiO}_{2} \leq 100 \mathrm{mmHg}$

*Calculated according to Sinha. (17), see formula in Additional file 1: Appendix 4

${ }^{* *}$ Calculated according to Morales-Quinteros et al. (18), see formula in Additional file 1: Appendix 4

Additional file 1: Fig. s9, Additional file 1: Fig. s10). However, it was associated with an elevated ICU risk of mortality in a time-varying Cox regression model (Additional file 1: Fig. s11).

The Cox proportional hazards model, in covariate balanced population analysis, showed that highly predictive variables for ICU mortality were age, body mass index, high levels of C-reactive protein, procalcitonin, ferritin, D-dimers, and the presence of chronic obstructive pulmonary disease (Additional file 1: Fig. s12). Variables that were highly predictive of ICU mortality in patients, who required invasive mechanical ventilation, are shown in Additional file 1: Fig. s13. In mechanically ventilated patients, high D-dimers were significantly associated with mortality independently of the static respiratory system compliance (Additional file 1: Fig. s14).

Sensitivity analyses assessing 90-day ICU mortality risk in the un-balanced population in crude models (Additional file 1: Fig. s15, Additional file 1: Table s5) and multivariable-adjusted models (Additional file 1: Fig. s16,
Additional file 1: Fig. s17, Additional file 1: Fig. s18, Additional file 1: Fig. s19), with and without between-centre random effects term, showed the same associations as the covariate balanced population analysis.

\section{Discussion}

In this retrospective, baseline covariate balanced, multicentre cohort of 1093 critically ill non-invasively ventilated COVID-19 ICU patients, 897 (82\%) eventually required endotracheal intubation and $310(28 \%)$ died during their ICU stay. The need for endotracheal intubation and invasive mechanical ventilation was significantly lower in patients supported by HFT and NIV than in those receiving oxygen mask therapy at ICU admission. Additionally, patients supported by means of HFT had a lower risk of ICU mortality than patients supported with oxygen masks and NIV.

Debate around the optimal choice of non-invasive oxygenation support in acute hypoxemic respiratory failure has re-emerged within the framework of the COVID-19 


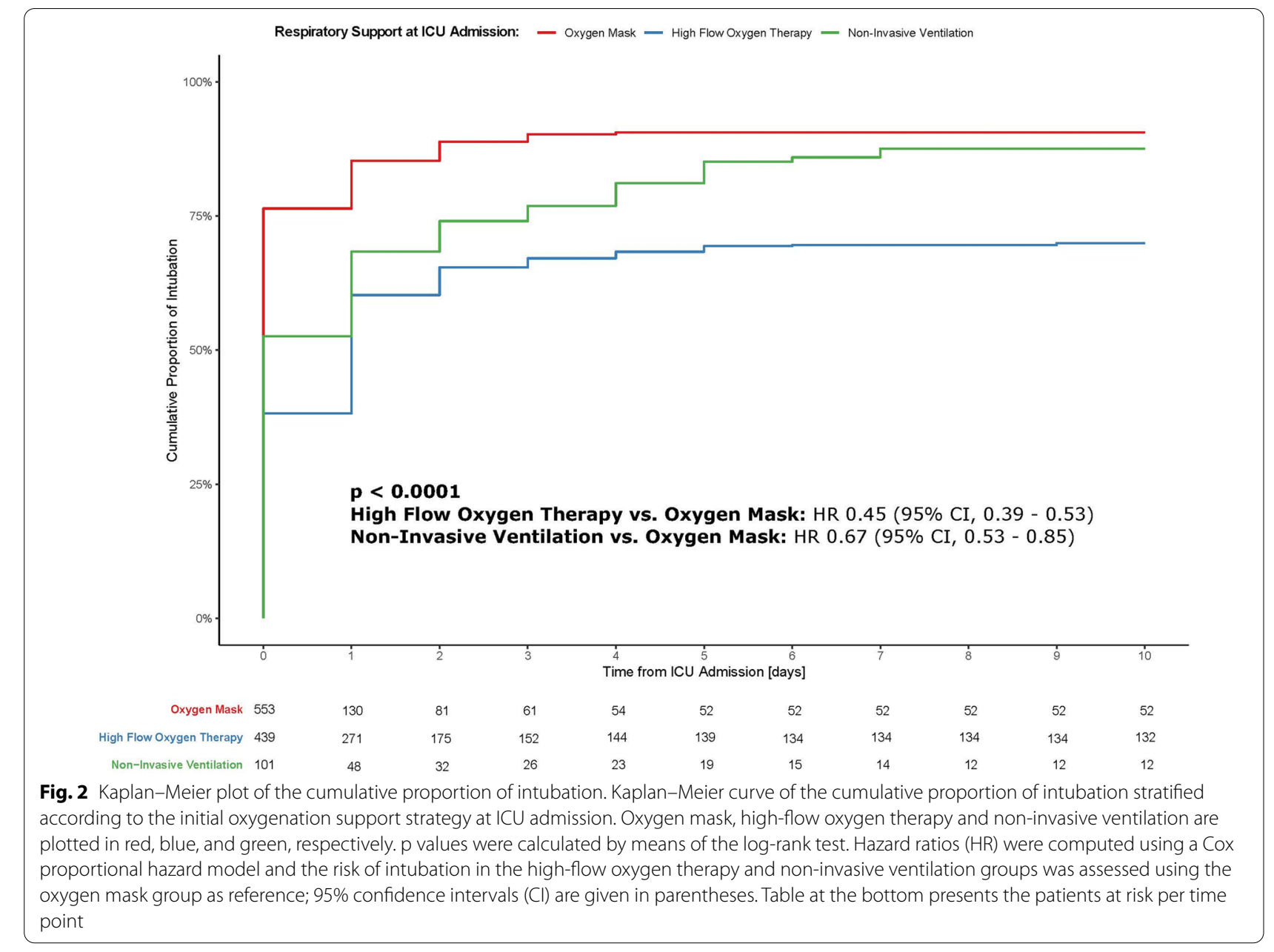

(See figure on next page.)

Fig. 3 Kaplan-Meier plot of the cumulative survival in the intensive care unit. Kaplan-Meier curve of the cumulative intensive care survival was stratified according to the initial oxygenation support strategy at admission to the intensive care unit. Subplot (a) refers to all patients included in the analysis. Subplot (b) considers only patients pending probably intubation and invasive mechanical ventilation. Oxygen mask, high-flow oxygen therapy and non-invasive ventilation are plotted in red, blue, and green, respectively. $p$ values were calculated by means of the log-rank test. Hazard ratios (HR) were computed by means of a Cox proportional hazard model. The risk of intensive care unit mortality in the high-flow oxygen therapy and non-invasive ventilation groups was assessed using the oxygen mask group as reference; $95 \%$ confidence intervals (Cl) are given in parentheses. Table at the bottom shows the patients at risk per time point

pandemic $[1,12,13,15,21-23]$. The association between the use of HFT or NIV and a reduction in endotracheal intubation rates compared to oxygen mask has yielded ambiguous results [24-26]. The two largest randomized trials to date did not find reductions in endotracheal intubation rates benefitted patients supported with HFT or NIV compared to those treated with an oxygen mask [27, 28] These findings may have several explanations: different populations and etiologies of acute hypoxemic respiratory failure, different inclusion and exclusion criteria, non-identical methodological approaches to the use of non-invasive techniques, and different criteria to declare a failed non-invasive oxygenation attempt. Furthermore, the primary outcomes of these studies were not the same.

In SARS-CoV-2-induced hypoxemic respiratory failure, however, the use of HFT and NIV was superior to oxygen mask in limiting progression to invasive mechanical ventilation, supporting our findings $[29,30]$. The reason for this efficacy of HFT and NIV is possibly explained by their physiological effects in terms of improvements in gas exchange, decreases in respiratory muscle effort, and a generally ameliorated sensation of dyspnea as 


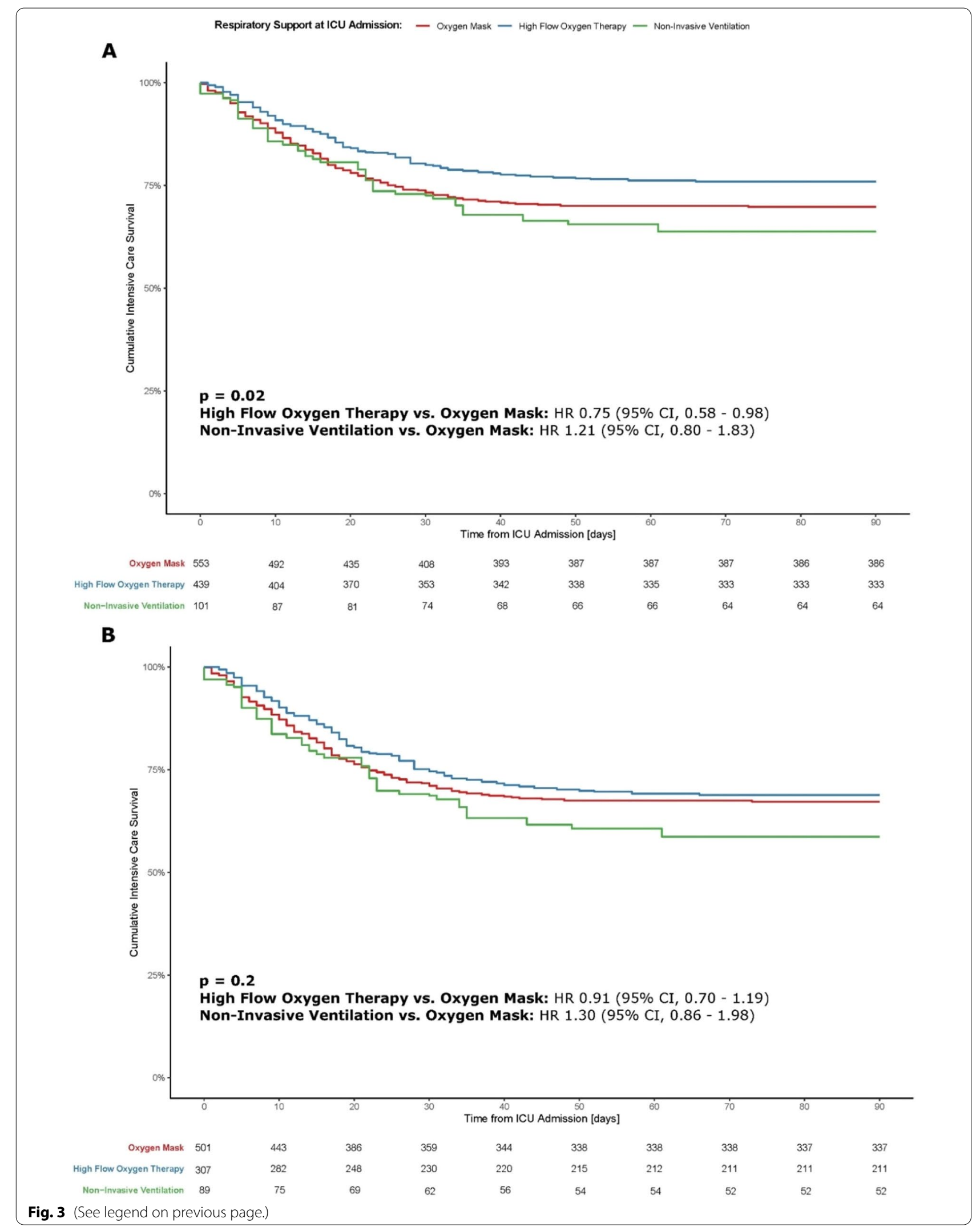


compared to oxygen masks [31-37]. Several mechanisms may explain these beneficial mechanisms. First, the increase in end-expiratory lung volume with some degree of alveolar recruitment induced by PEEP could decrease shunt and consequently improve $\mathrm{PaO}_{2}$ [32-34]. Second, as compared to facial oxygen masks, HFT generates a dead space washout of the upper airways, allowing a more homogeneous distribution of tidal volume [32]. Third, HFT induces a decrease in respiratory rate with less effort per breath with unchanged tidal volumes, thus suggesting better lung compliance [32]. These effects may help decrease inspiratory muscle effort, reduce the chemical drive to breath and, in turn, decrease the sensation of dyspnea [35]. It is of note, however, that we are dealing with a single disease (COVID-19) that is typically vasculopathic and accompanied by widespread endothelialitis $[38,39]$. Such physiopathological derangements may profoundly modify the ventilation/perfusion relationships and hypoxic pulmonary vasoconstriction [40]. In addition, SARS-CoV-2 exerts direct effects on the carotid bodies and the central nervous system [39], which may alter the central respiratory drive [21].

It is also of interest in our study that we observed lower endotracheal intubation rates in HFT and NIV treated patients than in oxygen mask treated patients. However, only the use of HFT was associated with a reduction in mortality rate. This result is consistent with the landmark trial of Frat et al. [27] but in contrast with the remaining literature [28-30]. Recent data [41] indicate that when compared to early intubation, HFT is associated with an increase in ventilator-free days and no differences in hospital mortality. The lower mortality in the HFT group in our study could directly reflect the lower intubation rate in this population.

In our study, we observed a trend towards higher mortality in the NIV group than in the oxygen mask group despite the lower intubation rate. It has been hypothesized that early endotracheal intubation and lungprotective ventilation in patients failing non-invasive oxygenation support and eventually requiring invasive mechanical intubation is associated with a protective effect. In a large series of ADRS patients, Kangelaris et al. [42] showed that mortality in those who were intubated early (on day 1 of ARDS diagnosis) was significantly lower than in those intubated later (between 2 and 4 days after ARDS diagnosis): the adjusted risk of death was 2.37 times higher for late intubation than for early intubation. Other authors, however, did not observe these effects in COVID-19 patients [43, 44]. More than time per se, several authors have suggested that what occurs during noninvasive oxygenation support is relevant. Carteaux [45] and Frat [46] showed that rather than the time to intubation, large tidal volumes-and thus large transpulmonary pressure swings-during NIV are associated with worse outcomes. Hence, one could argue that the total dose of injury (i.e. size of tidal volume and dissipated pressure times duration of ventilation) may eventually be harmful.

Our data show a clear association between the time from ICU admission to intubation and an increased risk of mortality (see Additional file 1: Fig. s11), possibly explaining the trend towards higher mortality in intubated patients previously undergoing NIV support. Additionally, patient self-inflicted lung injury, through the generation of large swings in transpulmonary pressures with excessive tidal volumes and cycling opening and alveolar collapse phenomena, has been postulated as a primary driver of mortality in NIV supported patients [45-47]. In addition, other relevant phenomena occurring in non-intubated spontaneously breathing subjects with acute hypoxemic respiratory failure include expiratory airway closure [48], pendelluft with regionally large swings of transpulmonary pressure [49] and, possibly bronchiolotrauma [50]. Finally, the large transpulmonary pressure swings during spontaneous breathing, which generate high pulmonary transmural vascular pressures, also enhance pulmonary oedema $[47,51]$. However, in our study, shortly after endotracheal intubation and irrespectively of the non-invasive oxygenation strategy used, we found that respiratory mechanics and gas exchange were comparable between groups. This observation suggests that, when used for a relatively short period of time, none of these three very different non-invasive oxygenation techniques seem to be worse than the other in terms of magnifying the amount of lung injury (as clinically assessed in terms of gas exchange and basic respiratory system mechanics).

Whether the development of a full-blown patient self-inflicted lung injury requires a time-course threshold, as suggested by the increased mortality in patients intubated after more than 3 days under non-invasive respiratory support (Additional file 1: Fig. s11), or it is governed by another form of time-to-event relationship, is unknown [47]. Conversely, patient self-inflicted lung injury could primarily be biotraumatic, exacerbating pulmonary inflammation. And only secondarily, at a later stage (i.e. invasive mechanical ventilation acting as a "second hit"), would this lead to diffuse alveolar damage and alveolar remodelling, and thus impair respiratory system mechanics [30, 47, 49, 52].

Our results stand in contrast with those from a recent randomized controlled trial that compared HFT and NIV as treatment for hypoxemic respiratory failure. The authors found that mortality rates were comparable in the two groups [53]. Nevertheless, it is of note that the patients in Grieco's study were treated by means of a helmet rather than a facemask. Recent evidence suggests 
that the limitations of NIV in oxygenation support of hypoxemic respiratory failure are inherent to the facemask interface and that the use of a helmet is associated with fewer air leaks, higher and more stable PEEP levels during prolonged periods of time, improved oxygenation, and reduced inspiratory efforts [31, 54]. Our study has a number of limitations. First, the cohort of patients was collected retrospectively and lacked any degree of randomization, formally impeding an unbiased treatment effect. Nonetheless, the baseline covariate balancing performed enabled mitigation of most objectively assessable confounders. Second, the cohort may be subject to selection bias as during the pandemic outbreak, patients who were treated with the same non-invasive oxygenation techniques but were not admitted into the ICU were not included in the study. Third, in the absence of a study protocol, the choice of oxygenation support strategy and the decision to proceed towards endotracheal intubation and mechanical ventilation were likely variable. It is not known whether the choice of one technique or another was based on clinical decision or equipment availability. Nonetheless, the data presented faithfully represent usual care practice during the pandemic. Fourth, no data on longitudinal inflammatory parameters or pulmonary mechanics data were available, preventing investigation of long-term mechanistic effects associated with the choice of non-invasive oxygenation support strategy. Fifth, neither gas exchange nor other respiratory variables were collected before invasive mechanical ventilation was started. Sixth, mortality was available from the ICU only, impeding analysis of hospital or absolute survival. Nevertheless, the largest proportion of mortality in critically ill patients occurs in the ICU, and our patients were followed for up to 90 days therein. Seventh, no specifications were available regarding the type of NIV interface and settings employed, albeit most probably only facemasks were used. Eighth, the temporal gap between ICU admission and endotracheal intubation was only available on a scale of days, thus impeding a more granular analysis. Ninth, the imbalance in group sizes could have led to a lack of power to recognize higher mortality in the NIV supported group. Tenth, as we do not have data from a more contemporaneous cohort, we cannot assess the dynamic effects of the pandemic-such as changing care practices and new pharmacologic treatments-on the reported effects. Finally, the potential role of unmeasured confounders cannot be excluded.

\section{Conclusion}

In critically ill COVID-19 ICU patients with acute hypoxemic respiratory failure, the use of HFT was associated with lower intubation and ICU mortality rates than those in patients supported by means of oxygen mask and NIV.
Given the inconclusive data in the ICU population, the choice of HFT as a primary non-invasive oxygenation support strategy seems warranted.

\section{Abbreviations}

COVID-19: Coronavirus disease-2019; ICU: Intensive care unit; SARS-CoV-2: Severe acute respiratory syndrome coronavirus 2; SpO2: Pulse oximeter oxygen saturation; Cl: Confidence interval; ARDS: Acute respiratory distress syndrome; PEEP: Positive end-expiratory pressure; Oxygen mask: Standard non-rebreather oxygen masks; HFT: High-flow oxygen therapy administered through large-bore nasal cannulas; NIV: Non-invasive positive pressure ventilation; CPAP: Continuous positive airway pressure.

\section{Supplementary Information}

The online version contains supplementary material available at https://doi. org/10.1186/s13054-022-03905-5.

Additional file 1: e-Table 1: Percentage of missing values. e-Appendix 1: Multiple imputations of missing data and technique break down. e-Figure 1: Multiple imputation - convergence plots. e-Figure 2: Multiple imputation - distribution plots. e-Table 2: Imputation model fit. e-Appendix 2: Extended Statistical Methodology. e-Figure 3: Covariate balancing models - model fit comparison. e-Figure 4: Covariate balancing models weights comparison. e-Appendix 3: Study information. e-Table 3: Overall un-balanced population. e-Table 4: Un-balanced study population. e-Figure 5: Final covariance balancing model - model fit. e-Figure 6: Final covariate balancing model - individual variable distributions. e-Figure 7: Final covariate balancing model - model weights. e-Figure 8: Static compliance versus time from ICU admission until intubation. e-Figure 9: Driving pressure versus time from ICU admission until intubation. e-Figure 10: $\mathrm{PaO}_{2} / \mathrm{FiO}_{2}$ ratio versus time from ICU admission until intubation. e-Figure 11: Cox time varying model for influence of time until intubation on ICU mortality. e-Figure 12: Multivariable Cox proportional hazards model for in-ICU mortality (overall and covariance balanced). e-Figure 13: Multivariable Cox proportional hazards model for in-ICU mortality (only intubated and covariance balanced). e-Figure 14: KaplanMeier curve for ICU mortality - compliance vs. D-dimers. e-Figure 15: Kaplan-Meier curve for ICU mortality in unbalanced population. e-Table 5: Cox mixed-effects model with between-center random effects term (unbalanced). e-Figure 16: Multivariable Cox proportional hazards model for in-ICU mortality (overall and unbalanced). e-Figure 17: Multivariable Cox proportional hazards model for in-ICU mortality (only intubated and unbalanced). e-Figure 18: Multivariable Cox mixed-effects model with between-center random effects term for in-ICU mortality (overall study population - unbalanced). e-Figure 19: Multivariable Cox mixed-effects model with between-center random effects term for in-ICU mortality (only intubated - unbalanced). e-Appendix 4: Formulas.

\section{Acknowledgements}

The authors thank Carolyn Newey for her assistance in editing the manuscript. In addition to the authors (in bold), the UCIsCAT study group includes the following collaborators: Hospital Universitari General de la Vall d'Hebron, Barcelona: R.Ferrer, O.Roca, X. Nuvials, J.C Ruiz, E. Papiol. Hospital Universitari de Bellvitge, L'Hospitalet de Llobregat : R. Máñez, V.D Gumicio. Hospital Clínic i Provincial de Barcelona, Barcelona: E.Sandoval, G.Muñoz, D.Toapanta, P.Castro, J. Osorio. Hospital del Mar, Barcelona: J.R Masclans, R. Muñoz-Bermúdez, F. Parrilla, P. Pérez-Teran, J. Marin-Corral. Hospital de Sant Joan Despí Moisès Broggi, Sant Joan Despí: A. Mas, B. Cancio, S.Hernández-Marín, M.R. Koborzan , C.A Briones. Hospital Mútua de Terrassa, Terrassa: J. Trenado. Althaia (Xarxa Assistencial Universitària de ManresaM. Martínez), Manresa: R.Fernández. Hospital Universitari Doctor Josep Trueta de Girona, Girona: J.M Sirvent, P. Sebastian, X. Saiz. Hospital General De Cataluña, Sant Cugat del Vallès: M. Martínez. Hospital Universitari Sagrat Cor—Grup Quirónsalut, Barcelona: M. Ibarz. Hospital General de Granollers, Granollers: P.Garro, C.Pedrós, E.Vendrell. Hospital General de Vic (Consorci Hospitalari de Vic), Vic: J.L Lopera. Hospital Universitari de Tarragona Joan XXIII, Tarragona: M. Bodí, A. Rodríguez, G. 
Moreno. Hospital de Mataró, Mataró: J.C Yébenes-Reyes. Hospital d'Igualada, Igualada: C. Triginer. Hospital Sant Joan de Reus, Reus: I. Vallverdú. Hospital de Santa Caterina, Salt: A. Baró, M. Morales. Hospital de Sant Pau i Santa Tecla, Tarragona: F. Bodí. Hospital HM Delfos, Barcelona: P.Saludes, J-R.Cervelló. Hospital El Pilar_-Grup Quirónsalut, Barcelona: M. Valencia. Hospital de Tortosa Verge de la Cinta, Tortosa: F. Roche-Campo, D. Franch-Llasat. Clínica Sagrada Família, Barcelona: A.Huerta, P.Santigosa. Hospital Sant Joan de Déu, Esplugues de Llobregat: F.J Cambra, S. Benito. Hospital Santa María, Lleida: C.Barberà. Hospital ASEPEYO de Barcelona, Sant Cugat del Vallés: J.Echevarría. Hospital de la Santa Creu i Sant Pau, Barcelona: J. Mancebo, P.Vera, J-A.Santos, J.Baldirà, A-J.Betbesé, M. Izura, I.Morán, J-C.Suárez, L.Zapata, N.Rodríguez, M.Torrens, A.Cordón, C.Gomila, M.Flores, A.Segarra, M.Morales, L.Mateo, M.Martos, C.González-Isern (Coordinating centre)

\section{Authors' contributions}

PDWG, CGI and JM take responsibility for the integrity of the data and the accuracy of the data analysis. PDWG, CGI and JM conceived, designed and coordinated the research. PDWG, CGI and JM were responsible for data acquisition and interpretation. PDWG performed statistical analysis. PDWG, CGI and JM drafted the manuscript. All authors participated in collection of data, critically revised the draft of the manuscript, reviewed and approved the final version and agreed to submit the manuscript for publication.

\section{Funding}

This study had no funding.

\section{Availablity of data materials}

The dataset of the current study is available from the corresponding author on reasonable request.

\section{Declarations}

\section{Ethics approval and consent to participate}

The ethics committee at the coordinating centre (Hospital Universitari de la Santa Creu i Sant Pau, Barcelona) approved the study protocol (UCIS-CAT 20/151 OBS) and waived the need for informed consent. Participating centres complied with all local requirements.

\section{Consent for publication}

Not applicable.

\section{Competing interests}

P.D Wendel-Garcia has nothing to disclose. A. Mas declares teaching fees from Fundació Parc Tauli, outside the submitted work. C. González-Isern has nothing to disclose. R. Ferrer declares personal fees from MSD, GSK, Alexion, Pfizer, Shionogi, Menarini and Gilead, outside the submitted work. R. Máñez has nothing to disclose. J.R. Masclans declares grants and research support from Fisher\&Paykel and fees from Dextro payed to his Institution, outside the submitted work. E. Sandoval, P. Vera, J. Trenado, R. Fernández, J.M. Sirvent, M. Martínez, M. Ibarz, P. Garro, J.L. Lopera, M. Bodí, J.C. Yébenes-Reyes, C. Triginer, I. Vallverdú, A. Baró, F. Bodí, P. Saludes, M. Valencia, F. Roche-Campo, A. Huerta, F.J. Cambra, C. Barberá, J. Echeverria, and O. Peñuelas have nothing to disclose. J. Mancebo declares personal fees from Medtronic and Janssen, a research grant from Covidien/Medtronic and the Canadian Institutes of Health Research and he is consultant for Vyaire, all outside the submitted work.

\section{Author details}

1 Institute of Intensive Care Medicine, University Hospital of Zurich, Zurich, Switzerland. ${ }^{2}$ Intensive Care Department, Hospital de Sant Joan Despí Moisès Broggi, Sant Joan Despí, Spain. ${ }^{3}$ Medical Technology Department, Hospital de La Santa Creu I Sant Pau, Barcelona, Spain. ${ }^{4}$ Intensive Care Department/SODIR Research Group, Hospital Universitari General de La Vall d'Hebron, Barcelona, Spain. ${ }^{5}$ Intensive Care Department, L'Hospitalet de Llobregat, Barcelona, Spain. ${ }^{6}$ Intensive Care Department, Hospital del Mar, GREPAC Research Group - IMIM, Department Ciències, Experimentals I de La Salut (DCEXS) UPF, Barcelona, Spain. ${ }^{7}$ Cardiovascular Surgery Department, Hospital Clínic de Barcelona, Barcelona, Spain. ${ }^{8}$ Intensive Care Department, Hospital de La Santa Creu I Sant Pau, Barcelona, Spain. ${ }^{9}$ Intensive Care Department, Hospital Mútua de Terrassa, Terrassa, Spain. ${ }^{10}$ Intensive Care Department, Althaia, Xarxa Assistencial Universitària de Manresa, Manresa, Spain. ${ }^{11}$ Intensive Care Department,
Hospital Universitari Doctor Josep Trueta de Girona, Girona, Spain. ${ }^{12}$ Intensive Care Department, Hospital General De Cataluña, Sant Cugat del Vallès, Spain. ${ }^{13}$ Intensive Care Department, Hospital Universitari Sagrat Cor - Grup Quirónsalut, Barcelona, Spain. ${ }^{14}$ Intensive Care Department, Hospital General de Granollers, Granollers, Spain. ${ }^{15}$ Intensive Care Department, Hospital General de Vic, Consorci Hospitalari de Vic, Vic, Spain. ${ }^{16}$ Intensive Care Department, Hospital Universitari de Tarragona Joan XXIII, Tarragona, Spain. ${ }^{17}$ Intensive Care Department, Hospital de Mataró, Mataró, Spain. ${ }^{18}$ Intensive Care Department, Hospital d'Igualada, Igualada, Spain. ${ }^{19}$ Intensive Care Department, Hospital Sant Joan de Reus, Reus, Spain. ${ }^{20}$ Intensive Care Department, Hospital de Santa Caterina, Salt, Spain. ${ }^{21}$ Intensive Care Department, Hospital de Sant Pau I Santa Tecla, Tarragona, Spain. ${ }^{22}$ Intensive Care Department, Hospital HM Delfos, Barcelona, Spain. ${ }^{23}$ Intensive Care Department, Hospital El Pilar - Grup Quirónsalut, Barcelona, Spain. ${ }^{24}$ Intensive Care Department, Hospital de Tortosa Verge de La Cinta, Tortosa, Spain. ${ }^{25}$ Intensive Care Department, Clínica Sagrada Família, Barcelona, Spain. ${ }^{26}$ Pediatric Intensive Care Department, Hospital Sant Joan de Déu de Barcelona, Esplugues de Llobregat, Spain. ${ }^{27}$ Intensive Care Department, Hospital Santa Maria, Lleida, Spain. ${ }^{28}$ Intensive Care Department, Hospital ASEPEYO de Barcelona, Sant Cugat del Vallés, Spain. ${ }^{29}$ Intensive Care Department Hospital, Universitario de Getafe, CIBER Enfermedades Respiratorias, CIBERES (Spain), Madrid, Spain. ${ }^{30}$ Institut d, Investigació Biomèdica Sant Pau, ', Servei Medicina Intensiva, Hospital Universitari Sant Pau, Barcelona, Spain. ${ }^{31}$ Hospital Universitari General de La Vall d'Hebron, Barcelona, Spain. ${ }^{32}$ Hospital Universitari de Bellvitge, L'Hospitalet de Llobregat, Barcelona, Spain. ${ }^{33}$ Hospital Clínic I Provincial de Barcelona, Barcelona, Spain. ${ }^{34} \mathrm{Hospital}$ del Mar, Barcelona, Spain. ${ }^{35}$ Hospital de Sant Joan Despí Moisès Broggi, Sant Joan Despí, Spain. ${ }^{36}$ Hospital Mútua de Terrassa, Terrassa, Spain. ${ }^{37}$ Althaia (Xarxa Assistencial Universitària de Manresa), Manresa, Spain. ${ }^{38}$ Hospital Universitari Doctor Josep Trueta de Girona, Girona, Spain. ${ }^{39} \mathrm{Hospital}$ General De Cataluña, Sant Cugat del Vallès, Spain. ${ }^{40} \mathrm{Hospital}$ Universitari Sagrat Cor - Grup Quirónsalut, Barcelona, Spain. ${ }^{41}$ Hospital General de Granollers, Granollers, Spain. ${ }^{42}$ Hospital General de Vic (Consorci Hospitalari de Vic), Vic, Spain. ${ }^{43}$ Hospital Universitari de Tarragona Joan XXIII, Tarragona, Spain. ${ }^{44}$ Hospital de Mataró, Mataró, Spain. ${ }^{45}$ Hospital d'Igualada, Igualada, Spain. ${ }^{46}$ Hospital Sant Joan de Reus, Reus, Spain. ${ }^{47}$ Hospital de Santa Caterina, Salt, Spain. ${ }^{48} \mathrm{Hospital}$ de Sant Pau I Santa Tecla, Tarragona, Spain. ${ }^{49} \mathrm{Hospital}$ HM Delfos, Barcelona, Spain. ${ }^{50} \mathrm{Hospital}$ El Pilar - Grup Quirónsalut, Barcelona, Spain. ${ }^{51}$ Hospital de Tortosa Verge de La Cinta, Tortosa, Spain. ${ }^{52}$ Clínica Sagrada Família, Barcelona, Spain. ${ }^{53} \mathrm{Hospital}$ Sant Joan de Déu, Esplugues de Llobregat, Spain. ${ }^{54} \mathrm{Hospital}$ Santa María, Lleida, Spain. ${ }^{55} \mathrm{Hospital}$ ASEPEYO de Barcelona, Sant Cugat del Vallés, Spain. ${ }^{56}$ Hospital de La Santa Creu I Sant Pau, Barcelona, Spain.

Received: 5 November 2021 Accepted: 26 January 2022

Published online: 08 February 2022

\section{References}

1. Azoulay E, de Waele J, Ferrer R, Staudinger T, Borkowska M, Povoa P, et al. International variation in the management of severe COVID-19 patients. Crit Care. 2020;24:486.

2. Schmidt M, Hajage D, Demoule A, Pham T, Combes A, Dres M, et al. Clinical characteristics and day-90 outcomes of 4244 critically ill adults with COVID-19: a prospective cohort study. Intensive Care Med. 2021;47:60-73.

3. Doidge JC, Gould DW, Ferrando-Vivas P, Mouncey PR, Thomas K, Shankar-Hari M, et al. Trends in intensive care for patients with COVID-19 in England, Wales, and Northern Ireland. Am J Respir Crit Care Med. 2021;203:565-74

4. Wendel Garcia PD, Fumeaux T, Guerci P, Heuberger DM, Montomoli J, Roche-Campo F, et al. Prognostic factors associated with mortality risk and disease progression in 639 critically ill patients with COVID-19 in Europe: Initial report of the international RISC-19-ICU prospective observational cohort. EClinicalMedicine. 2020;25:100449.

5. Botta M, Tsonas AM, Pillay J, Boers LS, Algera AG, Bos LDJ, et al. Ventilation management and clinical outcomes in invasively ventilated patients with COVID-19 (PRoVENT-COVID): a national, multicentre, observational cohort study. Lancet Respir Med. 2021;9:139-48.

6. Grasselli G, Zangrillo A, Zanella A, Antonelli M, Cabrini L, Castelli A, et al. Baseline characteristics and outcomes of 1591 patients infected 
With SARS-CoV-2 admitted to ICUs of the lombardy region Italy. JAMA. 2020;323:1574-81.

7. Cummings MJ, Baldwin MR, Abrams D, Jacobson SD, Meyer BJ, Balough EM, et al. Epidemiology, clinical course, and outcomes of critically ill adults with COVID-19 in New York City: a prospective cohort study. Lancet. 2020;395:1763-70.

8. Ferrando C, Suarez-Sipmann F, Mellado-Artigas R, Hernández M, Gea A, Arruti E, et al. Clinical features, ventilatory management, and outcome of ARDS caused by COVID-19 are similar to other causes of ARDS. Intensive Care Med. 2020;46:2200-11.

9. Karagiannidis C, Mostert C, Hentschker C, Voshaar T, Malzahn J, Schillinger $\mathrm{G}$, et al. Case characteristics, resource use, and outcomes of 10021 patients with COVID-19 admitted to 920 German hospitals: an observational study. Lancet Respir Med. 2020;8:853-62.

10. Richardson S, Hirsch JS, Narasimhan M, Crawford JM, McGinn T, Davidson $\mathrm{KW}$, et al. Presenting characteristics, comorbidities, and outcomes among 5700 patients hospitalized with COVID-19 in the New York City area. JAMA. 2020;323:2052-9.

11. Fernández R, González de Molina FJ, Batlle M, Fernández MM, Hernandez S, Villagra A. Soporte ventilatorio no invasivo en pacientes con neumonía por COVID-19: un registro multicéntrico español. Medicina Intensiva. 2021:45:315-7.

12. Tobin MJ, Jubran A, Laghi F. Noninvasive strategies in COVID-19: epistemology, randomised trials, guidelines, physiology. Eur Resp J. 2020:2004247.

13. Marini JJ, Gattinoni L. Management of COVID-19 respiratory distress. JAMA. 2020:323:2329-30.

14. Gorman E, Connolly B, Couper K, Perkins GD, McAuley DF. Non-invasive respiratory support strategies in COVID-19. Lancet Respir Med. 2021;9:553-6.

15. Fan E, Beitler JR, Brochard L, Calfee CS, Ferguson ND, Slutsky AS, et al. COVID-19-associated acute respiratory distress syndrome: is a different approach to management warranted? Lancet Respir Med. 2020;8:816-21.

16. Ranieri VM, Rubenfeld GD, Thompson BT, Ferguson ND, Caldwell E, Fan $\mathrm{E}$, et al. Acute respiratory distress syndrome: the Berlin Definition. JAMA. 2012;307:2526-33.

17. Sinha P, Calfee CS, Beitler JR, Soni N, Ho K, Matthay MA, et al. Physiologic analysis and clinical performance of the ventilatory ratio in acute respiratory distress syndrome. Am J Respir Crit Care Med. 2019;199:333-41.

18. Morales-Quinteros L, Neto AS, Artigas A, Blanch L, Botta M, Kaufman DA et al. Dead space estimates may not be independently associated with 28-day mortality in COVID-19 ARDS. Crit Care. 2021;25:171.

19. van Buuren S. Multiple imputation of discrete and continuous data by fully conditional specification. Stat Methods Med Res. 2007;16:219-42.

20. Austin PC, Stuart EA. Moving towards best practice when using inverse probability of treatment weighting (IPTW) using the propensity score to estimate causal treatment effects in observational studies. Stat Med. 2015;34:3661-79.

21. Tobin MJ, Laghi F, Jubran A. Why COVID-19 silent hypoxemia is baffling to physicians. Am J Respir Crit Care Med. 2020;202:356-60.

22. Tobin MJ, Laghi F, Jubran A. Caution about early intubation and mechanical ventilation in COVID-19. Ann Intensive Care. 2020;10:1-3.

23. Tobin MJ. Basing respiratory management of COVID-19 on physiological principles. Am J Respir Crit Care Med. 2020;201:1319-20.

24. Bellani G, Laffey JG, Pham T, Madotto F, Fan E, Brochard L, et al. Noninvasive ventilation of patients with acute respiratory distress syndrome. Insights from the LUNG SAFE study. Am J Respir Crit Care Med. 2017;195:67-77.

25. Rochwerg B, Granton D, Wang D, Helviz Y, Einav S, Frat J-P, et al. High flow nasal cannula compared with conventional oxygen therapy for acute hypoxemic respiratory failure: a systematic review and meta-analysis. Intensive Care Med. 2019:45:563-72.

26. Ferreyro BL, Angriman F, Munshi L, Del Sorbo L, Ferguson ND, Rochwerg $B$, et al. Association of noninvasive oxygenation strategies with all-cause mortality in adults with acute hypoxemic respiratory failure: a systematic review and meta-analysis. JAMA. 2020;324:57-67.

27. Frat J-P, Thille AW, Mercat A, Girault C, Ragot S, Perbet S, et al. High-flow oxygen through nasal cannula in acute hypoxemic respiratory failure. $\mathrm{N}$ Engl J Med. 2015;372:2185-96

28. Azoulay E, Lemiale V, Mokart D, Nseir S, Argaud L, Pène F, et al. Effect of high-flow nasal oxygen vs standard oxygen on 28-day mortality in immunocompromised patients with acute respiratory failure: the $\mathrm{HIGH}$ randomized clinical trial. JAMA. 2018;320:2099-107.

29. Demoule A, Vieillard Baron A, Darmon M, Beurton A, Géri G, Voiriot G, et al. High-flow nasal cannula in critically III patients with severe COVID19. Am J Respir Crit Care Med. 2020;202:1039-42.

30. Wendel Garcia PD, Aguirre-Bermeo H, Buehler PK, Alfaro-Farias M, Yuen B, David S, et al. Implications of early respiratory support strategies on disease progression in critical COVID-19: a matched subanalysis of the prospective RISC-19-ICU cohort. Crit Care. 2021;25:175.

31. Grieco DL, Menga LS, Raggi V, Bongiovanni F, Anzellotti GM, Tanzarella ES, et al. Physiological comparison of high-flow nasal cannula and helmet noninvasive ventilation in acute hypoxemic respiratory failure. Am J Respir Crit Care Med. 2019;201:303-12.

32. Mauri T, Turrini C, Eronia N, Grasselli G, Volta CA, Bellani G, et al. Physiologic effects of high-flow nasal cannula in acute hypoxemic respiratory failure. Am J Respir Crit Care Med. 2017;195:1207-15.

33. Mauri T, Spinelli E, Mariani M, Guzzardella A, Del Prete C, Carlesso E, et al. Nasal high flow delivered within the helmet: a new noninvasive respiratory support. Am J Respir Crit Care Med. 2019;199:115-7.

34. Mauri T, Alban L, Turrini C, Cambiaghi B, Carlesso E, Taccone P, et al. Optimum support by high-flow nasal cannula in acute hypoxemic respiratory failure: effects of increasing flow rates. Intensive Care Med. 2017:43:1453-63

35. L'Her E, Deye N, Lellouche F, Taille S, Demoule A, Fraticelli A, et al. Physiologic effects of noninvasive ventilation during acute lung injury. Am J Respir Crit Care Med. 2005;172:1112-8.

36. Tonelli R, Busani S, Tabbì L, Fantini R, Castaniere I, Biagioni E, et al. Inspiratory effort and lung mechanics in spontaneously breathing patients with acute respiratory failure due to COVID-19: a matched control study. Am J Respir Crit Care Med. 2021;204:725-8.

37. Tonelli $R$, Fantini $R$, Tabbì $L$, Castaniere I, Pisani L, Pellegrino MR, et al. Early inspiratory effort assessment by esophageal manometry predicts noninvasive ventilation outcome in de novo respiratory failure. A pilot study. Am J Respir Crit Care Med. 2020;202:558-67.

38. Ackermann M, Verleden SE, Kuehnel M, Haverich A, Welte $T$, Laenger $F$, et al. Pulmonary vascular endothelialitis, thrombosis, and angiogenesis in Covid-19. N Engl J Med. 2020;383:120-8.

39. Gupta A, Madhavan MV, Sehgal K, Nair N, Mahajan S, Sehrawat TS, et al. Extrapulmonary manifestations of COVID-19. Nat Med. 2020;26:1017-32.

40. Gattinoni L, Coppola S, Cressoni M, Busana M, Rossi S, Chiumello D. COVID-19 does not lead to a "typical" acute respiratory distress syndrome. Am J Respir Crit Care Med. 2020;201:1299-300.

41. Mellado-Artigas R, Ferreyro BL, Angriman F, Hernández-Sanz M, Arruti E, Torres A, et al. High-flow nasal oxygen in patients with COVID-19-associated acute respiratory failure. Crit Care. 2021;25:1-10.

42. Kangelaris KN, Ware LB, Wang CY, Janz DR, Zhuo H, Matthay MA, et al. Timing of intubation and clinical outcomes in adults with acute respiratory distress syndrome. Crit Care Med. 2016;44:120-9.

43. Hernandez-Romieu AC, Adelman MW, Hockstein MA, Robichaux CJ, Edwards JA, Fazio JC, et al. Timing of intubation and mortality among critically III Coronavirus Disease 2019 patients: a single-center cohort study. Crit Care Med. 2020;48:e1045-53.

44. Papoutsi E, Giannakoulis VG, Xourgia E, Routsi C, Kotanidou A, Siempos II. Effect of timing of intubation on clinical outcomes of critically ill patients with COVID-19: a systematic review and meta-analysis of non-randomized cohort studies. Crit Care. 2021;25:121.

45. Carteaux G, Millán-Guilarte T, De Prost N, Razazi K, Abid S, Thille AW, et al. Failure of noninvasive ventilation for de novo acute hypoxemic respiratory failure: role of tidal volume. Crit Care Med. 2016;44:282-90.

46. Frat JP, Ragot S, Coudroy R, Constantin JM, Girault C, Prat G, et al. Predictors of intubation in patients with acute hypoxemic respiratory failure treated with a noninvasive oxygenation strategy. Crit Care Med. 2018;46:208-15.

47. Brochard L, Slutsky A, Pesenti A. Mechanical ventilation to minimize progression of lung injury in acute respiratory failure. Am J Respir Crit Care Med. 2017;195:438-42.

48. Chen L, Del Sorbo L, Grieco DL, Shklar O, Junhasavasdikul D, Telias I, et al. Airway closure in acute respiratory distress syndrome: an underestimated and misinterpreted phenomenon. Am J Respir Crit Care Med. 2018;197:132-6. 
49. Yoshida T, Torsani V, Gomes S, De Santis RR, Beraldo MA, Costa EL, et al. Spontaneous effort causes occult pendelluft during mechanical ventilation. Am J Respir Crit Care Med. 2013;188:1420-7.

50. Borges JB. The plausibility of "bronchiolotrauma." Am J Respir Crit Care Med. 2018;197:1086-7.

51. Mancebo J. Noninvasive ventilation in acute hypoxemic respiratory failure: songs of love and hate. Crit Care Med. 2016:44:444-6.

52. Yoshida T, Uchiyama A, Matsuura N, Mashimo T, Fujino Y. Spontaneous breathing during lung-protective ventilation in an experimental acute lung injury model: high transpulmonary pressure associated with strong spontaneous breathing effort may worsen lung injury. Crit Care Med. 2012;40:1578-85.

53. Grieco DL, Menga LS, Cesarano M, Rosà T, Spadaro S, Bitondo MM, et al. Effect of helmet noninvasive ventilation vs high-flow nasal oxygen on days free of respiratory support in patients With COVID-19 and moderate to severe hypoxemic respiratory failure: the HENIVOT randomized clinical trial. JAMA. 2021;325:1731-43.

54. Patel BK, Wolfe KS, Pohlman AS, Hall JB, Kress JP. Effect of noninvasive ventilation delivered by helmet vs face mask on the rate of endotracheal intubation in patients with acute respiratory distress syndrome: a randomized clinical trial. JAMA. 2016;315:2435-41.

\section{Publisher's Note}

Springer Nature remains neutral with regard to jurisdictional claims in published maps and institutional affiliations.

- fast, convenient online submission

- thorough peer review by experienced researchers in your field

- rapid publication on acceptance

- support for research data, including large and complex data types

- gold Open Access which fosters wider collaboration and increased citations

- maximum visibility for your research: over $100 \mathrm{M}$ website views per year

At $\mathrm{BMC}$, research is always in progress.

Learn more biomedcentral.com/submissions 